\title{
PLAUTO EN EL REBUSCO DE APUNTAMIENTOS AUTÓGRAFOS DE QUEVEDO
}

\author{
Francisca Moya - Elena Gallego \\ Universidad de Murcia \\ fmoya@um.es - egallego@um.es
}

Al Profesor Ángel Martínez Fernández

\section{RESUMEN}

En estas páginas se analizan unos versos, que Quevedo copió de su mano, de tres comedias de Plauto; en ellos había descubierto expresiones latinas que la lengua española poseía con el mismo sentido. Son anotaciones que podían estar destinadas al tratado De la común razón de las letras y lenguas, que don Francisco pensaba publicar. Vieron la luz en 1859. Se conservan en el manuscrito M-530 de la Biblioteca Menéndez Pelayo. Las editamos y comentamos. En ellas se descubre de nuevo al Quevedo humanista.

Palabras ClaVE: Plauto, Quevedo, Rebusco de Apuntamientos autógrafos, Humanismo, salillum animae.

\section{PLAUTUS IN QUEVEDO'S REBUSCO DE APUNTAMIENTOS AUTÓGRAFOS}

\section{ABSTRACT}

In this work, the present authors have analyzed some verses from three comedies by Plautus, copied by Francisco de Quevedo verbatim. He had found out Latin expressions there used in Spanish with the same meaning. They are annotations which could be intended for the treaty entitled De la común razón de las letras y lenguas, which Quevedo was planning to publish. They were finally released in 1859. They are kept in manuscript M-530 at the Library Menéndez Pelayo. They are edited and commented on in this work. In these annotations, the reader will find Quevedo as an accomplished man-of-letters.

KEYwOrDs: Plautus, Quevedo, Rebusco de Apuntamientos autógrafos, Humanism, salillum animae.

Quevedo -es bien sabido y repetido- acostumbraba a poner anotaciones en los márgenes de los libros que leía, o a tomar notas y copiar textos que trasladaba a cuadernos u hojas sueltas. Las razones eran, sin duda, diferentes, y diferentes los libros que leía, mas todas las anotaciones nos hablan de Quevedo y constatan que era un extraordinario lector, que leyó, prácticamente, todo lo que se publicaba. Entre los libros que leyó con mucho aprovechamiento están las obras de los autores 
grecolatinos, como es igualmente sabido. Estas le sirven de inspiración, avalan sus ideas, y a él, desde luego, le gustaba citarlas ${ }^{1}$. Entre esos autores se encontraba Plauto.

Quevedo coincidía con Plauto en el ingenio, en la vis comica y en la brillantez creativa de su lengua. Quevedo admiraba al poeta latino; era capaz de descubrir, como pocos, las virtudes que destacaba en él Cicerón ${ }^{2}$. Es lógico que Plauto esté detrás de muchas páginas quevedianas, ya satíricas, ya dramáticas ${ }^{3}$. Sin embargo, las citas de textos de Plauto en la obra de Quevedo son muy pocas. Se limitan (en orden alfabético) a: Amphitruo 673, Asinaria 894, Poenulus 930, 950-954, 1033s., Rudens 535s. y Stichus 208. De ellas, la mayoría son indirectas; proceden, como el mismo Quevedo indica, de Paulo Festo o Nonio Marcelo; a ellos acudió buscando información sobre algunos términos, y en ellos encontró, entre otros autores, a Plauto como auctoritas'; es decir, el Quevedo lingüista se encuentra con un Plauto maestro del lenguaje. Pero no es indirecta la presencia de unos versos de Poenulus, en concreto, los versos 930-954. Los leyó, como podemos deducir, en una edición de Taubmannus. Las palabras del humanista en su comentario acerca de ellos lo movieron a enfrentarse con un texto de lengua no inteligible $y$ a tratar de explicarlo, haciéndolo él el primero, pues de este texto no se había ocupado antes, que se sepa, ningún humanista.

A los versos en latín hay que añadir la presencia de Plauto, en traducción castellana, en Las cuatro pestes y los cuatro fantasmas, con una cita de Mercator.

La escasez de citas de Plauto no implica, como decíamos, que nuestro autor no lo hubiera leído. Lo leyó. Y vienen a confirmarlo con contundencia unos versos que copió y reunió en una de sus muchas hojas, con intención, sin duda, de citarlos. Están incluidos en un conjunto de notas autógrafas de Quevedo que vieron la luz.

Esa costumbre de ir margeneando, como dice su primer biógrafo, Tarsia ${ }^{7}$, o de ir tomando notas, llevó a los bibliómanos del siglo XVIII a reunir cuanto de puño y letra de Quevedo hallaban, como informa Fernández-Guerra ${ }^{8}$, primer editor de estas

${ }^{1}$ Pueden verse en Moya (2014).

${ }^{2}$ Calificaba su iocandi genus, pues era un ejemplo del mismo, de elegans, urbanum, ingeniosum y facetum. Cf. CiC. off. 1, 104: Duplex omnino est iocandi genus, unum illiberale, petulans, flagitiosum, obscenum, alterum elegans, urbanum, ingeniosum, facetum, quo genere non modo Plautus noster et Atticorum antiqua comoedia, sed etiam philosophorum Socraticorum libri referti sunt (...).

${ }^{3}$ Puede verse, por ejemplo, lo que decía González de Salas, editor de las Poesías de Quevedo, en sus "Ilustraciones al Parnasso", en concreto a la Musa VI, Thalia, en la edición de Blecua (1999: 135), o Hernández Fernández (2006: 627-630), que se ocupa del teatro de Quevedo.

${ }^{4}$ Cf. Moya (2014: 339-343).

${ }^{5}$ Se encuentran en boca del cartaginés Hanno. Cf. Moya (2019: 600-604).

${ }^{6}$ Son los versos 472s. En ellos se apoya de modo poco imparcial para sustentar su teoría. Cf. Moya (2019: 594).

${ }^{7}$ Cf. Tarsia (1997: 34-35).

${ }^{8}$ Cf. Fernández-Guerra (1859: 501). Se leen en la primera nota de su edición. A su juicio, estas notas debían publicarse, aunque sabía que podían suscitar críticas. También reconoce que las ha ordenado en la medida de lo posible, ya que son 'cosas desligadas'. 
anotaciones; añade que, de ellos, fue el conde de Saceda el que mostró mayor diligencia en semejante búsqueda y quien permitió a don Antonio Sánchez sacar fiel y esmerada copia de sus hallazgos. Estas anotaciones, sigue informando, vinieron a poder de don Agustín Durán, director de la Biblioteca Nacional, el cual permitió a Fernández-Guerra darlas a la imprenta, incluidas en las Obras completas de Quevedo.

Estas anotaciones llevaban por título: Rebusco de apuntamientos autógrafos de Don Francisco de Quevedo Villegas. Se trata de una miscelánea muy variada y muy interesante, que ofrece útil información sobre Quevedo y su obra ${ }^{10}$. Casi un siglo después, en 1940, Astrana Marín publicaba en su Ideario de Don Francisco de Quevedo y Villegas, en el apartado dedicado a "El humanista polígrafo", alguno de estos "apuntamientos", aunque él prefiere referirse a ellos como "Observaciones raras a todo género de autores" ${ }^{\prime 1}$. Cinco años más tarde, Astrana Marín dio a la luz en sus Obras completas de Quevedo, un conjunto de anotaciones -apuntamientos u observacionesque tituló: Apuntes particulares y observaciones raras a todo género de autore ${ }^{12}$, cuyo contenido no es exactamente igual que el Rebusco, aunque coincide en la mayor parte con él. Se llamen apuntes, observaciones o apuntamientos, todos ellos son, ciertamente, otro testimonio del diálogo de Quevedo con sus libros. Entre ellos se encontraron, sin duda, las Comedias de Plauto.

El comediógrafo de Sarsina (Umbría), nacido a mitad del siglo III a.C., pero siempre actual, debió de entusiasmar a Quevedo por su ingenio y por la riqueza expresiva de su lengua; en él encontró textos, cuyo significado veía reflejado, prácticamente igual, en la lengua española, y los copió, acompañando a algunos de una explicación que justificaba el haberlos elegido. A Quevedo le interesaba mucho la lengua española, interés que queda reflejado en su España defendida, en concreto, en el capítulo cuarto, "De la lengua propia de España, de la lengua antigua y de la de ahora. La razón de su gramática, su propiedad, copia y dulzura"13. Había leído nuestro autor - $y$ aquí las citaba- una multitud de obras que trataban directa o indirectamente de la lengua española; sobre ellas emitía su juicio, no siempre favorable,

${ }^{9}$ Los apuntamientos se leen en Fernández-Guerra (1859: 501-507).

${ }^{10}$ Encontramos un buen número de textos de la Biblia y Patrística, y también abundan los clásicos grecolatinos. En algunos casos se indica cuál es su destino; en otros, hay que descubrirlo. Menéndez Pelayo (1950: III 143) da cuenta de la edición de Fernández-Guerra, y ofrece una información de este Rebusco, bajo "Francisco de Quevedo CDXXIII". Aunque su contenido es conocido y citado (López Poza, 1991: 101), estas anotaciones quevedianas merecen, a nuestro juicio, una nueva edición y estudio de conjunto.

${ }^{11}$ Cf. Astrana Marín (1940: 171-174). Encabeza sus cuatro observaciones o apuntamientos de esta manera: "Asimismo son interesantísimas sus Observaciones raras a todo género de autores, que alababa mucho don Tomás Tamayo de Vargas. De ellas elegimos estos fragmentos". Los "fragmentos", es decir, "apuntamientos" son los que llevan en Fernández-Guerra los números: XIV, XXXVI, XXXVII y XXXVIII. En cuanto al apartado "El humanista polígrafo", ocupa las páginas 169-180.

${ }^{12}$ Cf. Astrana Marín (1945: 1563-1583).

${ }^{13}$ El capítulo ocupa un buen número de páginas; cf. Moya-Miralles (2018: 101-161). 
a veces incluso muy desfavorable. Entre estas obras que conoció y valoró se encontraba el Origen de la lengua castellana de Bernardo de Alderete ${ }^{14}$. Es una obra repleta de citas de autores clásicos, sobre todo, latinos; Quevedo se sirve de ella con gran provecho, aunque a veces también corrija algunas ideas o trate de mejorar o completar otras; y, desde luego, alaba casi siempre a su autor. Quizá de esta obra partió la idea de querer también él aportar luz a nuestra lengua. Quevedo -según él mismo nos informa- ya estaba escribiendo un tratado que llevaba por título De la común razón de las letras y lenguas ${ }^{15}$, obra de la que, como de algunas otras mencionadas por él ${ }^{16}$, no sabemos nada. Pero sí creemos, sin embargo, poder afirmar que, muy probablemente, los textos de Plauto que Quevedo fue copiando y que se leen en el Rebusco de Apuntamientos iban destinados, como otros 'apuntamientos' de otros autores, a esta obra que quería publicar. Con Plauto y algunas de sus frases que en castellano, como reza su epígrafe, se utilizan con sentido semejante, él podría ilustrar algo de lo mucho que sabía sobre la relación y semejanzas de la lengua española y otras lenguas, en este caso, la latina ${ }^{17}$. Las editamos y comentamos ${ }^{18}$.

\section{EDICIÓN}

Nuestra edición de los textos de Plauto recogidos en el Rebusco de Apuntamientos autógrafos de Quevedo parte del manuscrito de la Biblioteca Menéndez Pelayo (sign. M-530 ${ }^{19}$; hemos consultado también el texto de Fernández-Guerra y Astrana Marín.

El manuscrito, de letra muy cuidada, no va numerado y consta de 65 páginas. Una especie de Índice, de mano diferente a la de los apuntamientos, los precede. Estos tampoco van acompañados siempre de numeración, aunque, en algunos

\footnotetext{
${ }^{14}$ El título completo reza así: Del origen y principio de la lengua castellana o romance que oi se usa en España por el doctor Bernardo Aldrete.

${ }^{15}$ Dice estar escribiéndolo en el mismo capítulo cuarto; al hablar de la letra T, promete que dará razón de la similitud que existe entre nuestro alfabeto y el de los Rabíes, hasta en las letras rasgadas. Cf. Moya-Miralles (2018: 118).

${ }^{16}$ Valga de ejemplo la Defensa de Homero, de la que le hablaba ya a Lipsius en su segunda epístola, de 22 de noviembre de 1604. Cf. Astrana Marín (1946: 7), y la última edición, traducción y estudio de Conde Parrado (2017: 45, 50 y 74). Sobre otras obras anunciadas y no publicadas, cf. Jauralde (1998: 931-934).

${ }^{17}$ Esta cuestión estaba bastante presente en el mencionado capítulo cuarto de España defendida.

${ }^{18}$ Se leen en Fernández-Guerra (1859: 507), Astrana Marín (1940: 172) y Astrana Marín (1945: 1580). También se recogen, como muestra de la importancia de Plauto en el teatro de Quevedo, en Hernández Fernández (2006: 627s.).

${ }^{19}$ Es el único que conocemos. En la Biblioteca Nacional el manuscrito 3706 contiene algunos apuntamientos a Cicerón (fols. 188-191v) y a Quintiliano y Tácito (fols. 319-321); cf. Jauralde (1998: 947 y 937), pero no está en él ni en otro, que sepamos, el de las Comedias de Plauto.
} 
de ellos, vemos dos: 1) una, a tinta, la primera (es de la misma mano que el apuntamiento), y 2) otra, a lápiz, lógicamente, posterior. El apuntamiento de los textos de Plauto lleva el número 128, el primero, y, añadido a lápiz, el número XXXVI. Mantenemos el número XXXVI, que se lee en la edición Fernández-Guerra ${ }^{20}$.

En nuestra edición regularizamos las referencias de los versos. El manuscrito, al ofrecer los textos latinos, informa de la comedia a la que pertenecen y, a la vez, de su ubicación en ella, con mención de acto, escena y, a veces, de número de verso en su respectiva escena. Sin embargo, esta información no se mantiene igual en todos los textos ${ }^{21}$, sin duda, porque se respeta lo que escribió Quevedo. En nuestra edición se ofrece información completa: número de acto en números romanos, el de escena en arábigos y, a continuación, el número que tienen los versos dentro de sus respectivas escenas. Añadimos, entre corchetes, la numeración que tienen en sus respectivas comedias.

Subsanamos algún error, y hemos corregido en un caso una lectio ${ }^{22}$.

Hemos mantenido el orden en que aparecen los versos en el manuscrito (también lo hacen las ediciones anteriores), y a los textos les hemos asignado una numeración, que en nuestro Comentario mantenemos.

A pie de página se indica: con $\mathrm{M}$ la información del manuscrito. FG y AM representan las ediciones de Fernández-Guerra (1859) y Astrana Marín (1945), de las que damos asimismo información ${ }^{23}$.

\section{REBUSCO DE APUNTAMIENTOS AUTÓGRAFOS DE QUEVEDO ${ }^{24}$ \\ XXXVI (Num ${ }^{\circ}$ 128)}

\section{Algunas frases latinas de Plauto Que literalmente Se usan} EN EL MISMO SENTIDO EN CASTELLANO.

1. Plautus, Menaechmi

a) ACT. I. SC. 2. vv. 43 y 45 [153 y 155$]^{25}$

. hunc comburamus diem.-

-Dies quidem iam ad umbilicum est dimidiatus mortuus.

b) ACT. III. SC. 2. v.6 $[471]^{26}$

Non, hercule, is sum, qui sum.

Así en español: "No seré yo quien soy".

${ }^{20}$ En Astrana Marín es el "apunte" LXI.

${ }^{21}$ Cf. infra.

${ }^{22}$ Cf. infra.

${ }^{23}$ No aportamos las variaciones que se limitan a escribir los números en arábigos o romanos, acto o act., etc.

${ }^{24}$ Así en FG. En M: "Rebusco de Apuntamientos autógrafos", situado delante del Índice [p. 1]. Primero se escribió "Apuntamientos"; posteriormente, el resto.

${ }^{25} \mathrm{M}$ : Menaechmi I scena II 43.

${ }^{26}$ M: 3. Acto. Scena 2. v. 6. M: Español. FB: hercle. 


\section{Mostellaria}

a) ACT. II. SC. 3. v. 44 [475] $]^{27}$

Capitalis caedis facta'st.

Capitalis por infesta.

b) ACT. II. SC. 3. v. $71[502]^{28}$

Defodit insepultum.

Defodere no es sepelire. Sepultus dicitur qui solemnibus inferis defoditur.

c) ACT. II. SC. 3. v.76 [508 $]^{29}$

Guttam haut habeo sanguinis.

Lo mismo en español: "No me quedó gota de sangre".

\section{Menaechmi}

ACT. III. SC. 1. vv. 16-17 [463-464] $]^{30}$

Cum corona exit foras.

Sublatum est convivium.

Esta era la señal.

\section{Mostellaria}

ACT. III. SC. 2. vv. 3-4 y 8 [692-693 y 697] $]^{31}$

prandium mihi uxor perbonum dedit.

nunc dormitum iubet me ire: minume.

non bonus somnus est de prandio: apage.

\section{Trinummus}

a) ACT. II. SC. 2. v. $63[345]^{32}$

Pol pudere quam pigere praestat, totidem litteris.

Dícese en español: "Más vale vergüenza en cara que mancilla en corazón".

b) ACT. II. SC. 2. v. $73[355]^{33}$

Deum virtute habemus.

${ }^{27}$ M: Mostellaria 2 Acto. Scena 2. v. 44. M: caedis facta'st/ Capitalis Por infesta. FB y AM omiten el segundo capitalis.

${ }^{28} \mathrm{M}$ omite información de verso. Se sobreentiende que pertenece al mismo acto y a la misma escena. FB y AM también la omiten.

${ }^{29} \mathrm{M}$ omite información de verso. Se sobreentiende que pertenece al mismo acto y a la misma escena. FB y AM también la omiten.

${ }^{30} \mathrm{M}$ : Menaechmi. Acto 3. Scena 1. v.16. FB omite la localización del texto.

${ }^{31}$ M y FB: Mostellaria. Acto 2. Scena 2. v. 3. AM: pradium. FB y AM: me iubet. AM: spage.

${ }^{32} \mathrm{M}$ : Trinnumo. Acto 2. Scena 2. M y FB: polpudere.

${ }^{33} \mathrm{M}$ : in Trinnumo Acto 2. Scena 2. 
c) ACT. II. SC. 4. VV. 91-93 [492-494] ${ }^{34}$

Salillum animae qui cum extemplo amisimus,

aequo ${ }^{35}$ mendicus atque ille opulentissimus

censetur censu ad Acherontem mortuus.

Decimos que el alma sirve de sal solamente al inútil, que solo le conserva el cuerpo.

\section{PRIMERAS CONCLUSIONES}

Hasta aquí lo que leemos en el manuscrito. Fernández-Guerra añadía al final entre paréntesis: "hoja en octavo" ${ }^{36}$, lo cual dejaba claro que todos estos textos y las palabras de Quevedo que a veces los acompañaban se hallaban juntos en una hoja de ese tamaño.

La lectura de estas anotaciones descubre que son notas para ser utilizadas por Quevedo. En ellas observamos cierto desorden, que habla quizá de cómo fue el encuentro de Quevedo con estos versos de Plauto. Es evidente que los juzgó de interés para ponerlos de ejemplo o detenerse en ellos en ese Tratado que tenía en la mente y también en la mesa de trabajo. Él tenía ya sus ideas sobre la relación de la lengua latina y la española, y es muy lógico que fuese "a buscar" avales en textos de la comedia plautina; sabía que el latín arcaico se "descubre" en muchísimas ocasiones en nuestra lengua española, como en otras romances, gracias a unos procesos sobre los que se discute, pero cuya realidad es evidente ${ }^{37}$.

Sean unas veces hallazgos o tengan detrás una búsqueda intencionada, lo cierto es que no están juntos los textos pertenecientes a una misma comedia; también se citan de modo diferente y, además, a unos se añade un comentario o una expresión que tiene su semejante en la lengua latina, mientras que en otros casos nada se dice. A ello se puede sumar que entre los textos de Plauto, precediendo a los versos de Trinummus, hay un texto de Séneca ${ }^{38}$, es decir, no hay solo textos de Plauto en este "Apuntamiento", como el epígrafe anunciaba.

En esta selección, en fin, encontramos solo tres comedias y de ellas un número muy reducido de versos ${ }^{39}$ : Menaechmi (vv. 153, 155, 471, 463-464), Mostellaria

${ }^{34} \mathrm{M}$ : Scena 3.

${ }^{35} \mathrm{M}, \mathrm{FB}$ y AM: aeque. Cf. Comentario.

${ }^{36}$ En M no aparece esta información. En otras ocasiones se indica incluso que se está copiando un autógrafo quevediano.

${ }^{37}$ Como es sabido, el latín llamado "vulgar" o "corriente", que daría lugar a las lenguas romances, coincidía bastante, pese a los siglos transcurridos, con el latín arcaico que presenta Plauto. Si se mantuvo este o si volvió a tomar vida, una vez desaparecida la presión del latín culto o literario, es cuestión discutida.

${ }^{38}$ Así leemos: Seneca VI, De Beneficiis, 32, 4: Regalis ingenii mos est, in praesentium contumeliam, amissa laudare, et his virtutem dare vera dicendi, a quibus iam audiendi periculum non est. Ningún comentario hace Quevedo a este texto.

${ }^{39}$ Como se ha dicho, están intercaladas y los versos tampoco son correlativos. 
(vv. 475, 502, 508, 692, 693, 697) y Trinummus (vv. 345, 346-347, 492-494). En cuanto a la correspondencia "literal" del español y el latín, solo rara vez es puesta de relieve. Es evidente que Quevedo sabía muy bien cuál era; quizá es menos fácil para nosotros. La breve parada que vamos a hacer en estos versos quizá nos ayude a su descubrimiento.

\section{COMENTARIO DE LOS TEXTOS}

\section{1.a. PlaVt. Men. 153 y 155}

\section{hunc comburamus diem.-}

-Dies quidem iam ad umbilicum est dimidiatus mortuus.

Quevedo no ha copiado el verso 154, ni el 153 completo, pues lo consideraría innecesario, pero el dictum plautino, comburere diem, que encontraba Quevedo en nuestra lengua, se ve más claro si incluimos lo que está omitido. Así leemos ${ }^{40}$ :

-Clam uxorem ubi sepulcrum habeamus, et hunc comburamus diem.

-Age sane igitur, quando aequum oras, quam mox incendo rogum?

-Dies quidem iam ad umbilicum est dimidiatus mortuus ${ }^{41}$.

Menecmo I quiere "quemar el día", es decir, enterrarlo (antes había mencionado el sepulcrum), en este caso, ponerlo en la pira. No deja Escobilla que acabe de hablar; lo interrumpe con su aplauso y apoyo; está dispuesto a encender la pira cuanto antes (quam mox), aunque pregunta cuándo. Menecmo I acabará su frase insistiendo en que el día está muerto (cf. sepulcrum y mortuus), ha llegado a su final, ad umbilicum, como si fuera el del rollo de papiro.

Plauto personifica el día y le da a la expresión un claro sentido metafórico ${ }^{42}$. Hay que quemar el día, y, una vez quemado, se podrá descansar, disfrutar, viviendo la noche -se sobreentiende que se disfrutaría cenando- $y$, sobre todo, en este caso, sin que la esposa lo supiera. "Quemar el día", con el sentido de "acabar el día" para empezar la noche -equiparando cena, disfrute, amigos, libertad, etc.-, es una creación muy propia de Plauto ${ }^{43}$, que se mantuvo y persiste.

${ }^{40}$ Situamos en redonda lo que no copió Quevedo.

${ }^{41}$ MeNECMO I: "Sin que se entere mi mujer, vayamos a dar sepultura y a encender la pira de este día... -EsCOBILla: ¡Vaya, eso sí que es hablar razonadamente! Así que, venga, vamos, ¡es hora ya de prender fuego a la pira? -MENECMO I: Porque el día ya está medio muerto, muerto hasta el ombligo". Traducción de Bravo (1995: I 627). Citaremos a partir de aquí solo con "Bravo".

${ }^{42}$ Cf. Fantham (1972: 102).

${ }^{43}$ Lo avala el gusto de Plauto por las metáforas mortuorias. Por ejemplo, un poco después habla de 'hacer el funeral a la cena', que no es otra cosa que ponerle fin. Cf. v. 492: fecisti funus med absente prandio. Utiliza, como antes, el término prandium, "comida", sobre todo, de mediodía, pero que puede referirse a comida en general, incluida la cena. 
Turnebus, al comentar comburamus diem, anotaba: Mortuo et exacto die Genium curemus et epulemur ${ }^{44}$, es decir, después de la muerte del día llega, por fin, nuestro tiempo, el tiempo de cenar. La cena -insistía- era como el diei bustum et sepulcrum ${ }^{45}$.

En cuanto a la expresión ad umbilicum, que se utiliza con verbos como ducere o pervenire, significa, como es bien sabido, "llegar al ombligo", al centro (ad medium) del rollo de pergamino, es decir, llegar al final de la lectura, y, metafóricamente, al final de cualquier $\operatorname{cosa}^{46}$; esta expresión, sin duda, era utilizada en tiempos de Quevedo y no la pasa por alto.

En este mismo Rebusco de Apuntamientos aparece un texto de Marcial: nigris pagina crevit umbilicis (MART. 5, 6, 15), al que don Francisco añade la explicación: Umbilicus, Porfirio teste, erat ornamentum, quod extremis partibus librorum vel ex osse, vel ex ligno, unde dicitur: res pervenit ad umbilicum. Nos cantoneras dicimus. FernándezGuerra añadía en nota: "La interpretación de umbilicus pertenece a Domitio Calderino en sus notas sobre aquel epigrama de Marcial. Solo añade Quevedo la equivalencia castellana”.

Ciertamente así es; Quevedo pudo leer en la edición de Marcial de Calderini y Merula ${ }^{47}$ la explicación de umbilicus. Pero advertimos que aquí no se lee Porphyrio teste, sino ut Porphyrio interpretatur. Quevedo quizá quiso -no se puede saber la razónmodificar el principio, sin darse cuenta de que cometía un error ${ }^{48}$. Por otra parte, 'cantoneras' no es exactamente lo mismo que umbilicus ${ }^{49}$.

1.b. PlaVt. Men. 471

Non, hercule, is sum, qui sum.

Estas palabras, que no necesitan mucha glosa, las dice, en un "aparte", Escobilla, que se siente ofendido por lo que ha visto. Menecmo I ha cenado, ha comido

${ }^{44} \mathrm{La}$ expresión comburere diem se ha interpretado como "pasar el día divirtiéndose". Ciertamente la cena, sobre todo, entre amigos, es igual a diversión, pero esta expresión sitúa la diversión-cena en el tiempo: una vez acabado el día (como dice Turnebus, exacto die o, como también se puede decir, combusto die).

${ }^{45}$ Cf. Gronovius (1829: 1984). Los comentaristas han aportado lugares paralelos a esta brillante expresión plautina; así, condere diem en Horacio, que deja claro que después del trabajo viene la alegría de la mesa; cf. Hor. carm. 4, 5, 29: Condit quisque diem collibus in suis / et vitem viduas ducit ad arbores; / hinc ad vina redit laetus / et alteris te mensis adhibet deum; e igual de claro lo vemos, por ejemplo, en STAT. silv. 4, 6, 3s: iam moriente die, rapuit me cena benigni / Vindicis.

${ }^{46}$ Se piensa que es llegar a la mitad del día, por estar en el centro el umbilicus, pero no parece, sobre todo, aquí, ser este el sentido que hay que darle.

${ }^{47}$ Cf. Martialis (1601: 245).

${ }^{48}$ Tendría que estar en ablativo (Porphyrione teste), ya que el nombre de este comentarista es de la tercera declinación. Quevedo también omite el final, pues en el final del comentario de Porfirión, que aporta Calderini, se explicaba la expresión ad umbilicum, añadiendo un id est, ad finem.

${ }^{49}$ Cf. DRAE, acepción 3 de Cantonera: "Pieza que se pone en las esquinas de las tapas de los libros o de las carpetas, de los muebles o de otros objetos para protegerlos, adornarlos o fijarlos a una base". 
y bebido, mientras que él no ha participado de esa comida. Tiene que vengarse. Sus palabras, a modo de amenaza, las encontramos, ciertamente, casi idénticas en castellano: "no seré yo quien soy", como indica Quevedo, omitiendo, lógicamente, hercule, que no se incluía en estas expresiones en castellano, aunque sí se solía sustituir por otros términos de tono variado, según las circunstancias ${ }^{50}$.

\section{2.a. Plavt Most. 475}

\section{Capitalis caedis facta'st.}

Esta frase la leyó Quevedo, en el ejemplar de su edición, con el término caedis, como aparece en el Rebusco, y así la había escrito en su hoja de cuaderno u hoja suelta; presentaba el término caedis, que es, como se sabe, la otra forma de nominativo (caedes o caedis) s1 $^{51}$ y que aquí parece tener el significado de "muerte violenta". Lo deja claro capitalis, que está indicando que lo que ha ocurrido allí es peligroso, es una muerte scelerata, impia ${ }^{52}$; o, como leemos en Quevedo, infesta. Sin duda, esa muerte-sobre todo, el muerto- va a causar mucho daño.

Quevedo sabía que se dice capitalis de algo que es pernicioso o pestífero, que, como recogía Nebrija en su Dictionarium, una ira "capital" es funesta, mortal (capitalis ira dixit Horatius quod exitialis, pestifera sit), o que capitalis se dice de un hombre que hace daño, criminal (capitalis homo dicitur a Cicero pro noxio atque pestilente) ${ }^{53}$. Y parece decir Quevedo que en la lengua española se encuentra la misma expresión que en Plauto ("muerte capital"), al aclarar que el adjetivo capitalis tiene un significado semejante al de infesta, o que está "por infesta". Con capitalis caedis facta'st Tranión le diría a Teoprópides que en la casa que a él interesa se había producido una "muerte capital", una muerte, sin duda, no natural, que es peligrosa para la vida ${ }^{54}$ de los demás, y, lógicamente, para Teoprópides lo podría ser. Desde luego, es un crimen, como dejará claro inmediatamente con: Capitale scelus factu'st - Scelus... factum est iam diu, antiquom et vetus. (vv. 475s.)

Esto leyó Quevedo, capitalis caedis, el sintagma se decía también en castellano. Pero este verso, tanto en manuscritos como ediciones, presenta variantes, y la más importante es aedes (también aedis) en vez de caedis. Con capitalis aedes se dice que

${ }^{50}$ En un amplio abanico.

${ }^{51}$ Como aedis o torquis, en vez de aedes, torques. Cf. Ramsay-Ramsay (2020: 146). Antes había explicado que "an atrocius murder was".

${ }_{52}$ Cf. Lambinus (1622: 446), que así explica la expresión capitalis caedes facta'st: scelerata, impia, et extremo supplicio digna caedes admissa est.

${ }^{53}$ En la edición de 1615, en p. 28r.

${ }^{54}$ Es uno de los significados del adjetivo capitalis. Cf. Ramsay-Ramsay (2020: 146-148), que ofrece y explica, con un buen número de ejemplos, los diferentes significados que, a partir de caput, asume este adjetivo; van de 'mortal', 'peligroso', 'terrible', a 'excelente' o 'de gran importancia'. 
"la casa está infestada", que es muy peligrosa, lógicamente por haberse cometido en ella un crimen ${ }^{55}$. Esta es, a nuestro juicio, la lectio facilior.

\section{2.b. PlaVT. Most. 502}

\section{Defodit insepultum.}

Leía Quevedo en los versos 501s. de Mostellaria: hospes... me defodit insepultum ("mi huésped me enterró insepulto"), y copió defodit insepultum, porque le llevaría a pensar, sobre todo, en un término prácticamente idéntico en forma y sentido, el español "insepulto".

El "personaje" (el que "había sido asesinado"), que se le apareció en sueños, según sus palabras, a Tranión, le había informado con esos dos términos de que él había sido asesinado en esa casa y echado a un hoyo abierto en la tierra, es decir, estaba "en tierra", enterrado, pero sin sepultura, porque, lógicamente, no había recibido los obligados honores que se rinden a los muertos. Quevedo explicará que no es lo mismo ser enterrado o puesto en un hoyo cavado en la tierra que ser sepultado. Para "ser sepultado" se precisan los honores de la sepultura y el "aparecido" había sido privado de solemnes inferiae. Así lo dice Quevedo: "Defodere no es sepelire; sepultus dicitur qui solemnibus inferis defoditur" 56 .

\section{2.c. PlaVt. Most. 508}

\section{Guttam haut habeo sanguinis.}

La expresión que lee Quevedo en Mostellaria no necesita comentario alguno. La correspondencia entre latín y castellano es evidente y así Quevedo lo explica: "Lo mismo en español: 'No me quedó gota de sangre'”. Está en boca de Teoprópides, que ha escuchado a Tranión y está asustado por lo que le ha dicho de esa casa maldita en la que mora un fantasma. Lógicamente, se queda sin sangre, como suele ocurrir en otras muchas ocasiones.

3. Plavt. Men. 463-464

Cum corona exit foras. Sublatum est convivium.

${ }^{55}$ Cf., por ejemplo, Riley (1852: 480). Así dice, comentando capitalis aedes facta est. "meaning that a murder had been committed in it".

${ }^{56}$ Literalmente: "Se dice sepultado el que ha sido enterrado con solemnes ofrendas a los manes", es decir, con las preceptivas exequias. Quevedo pudo encontrar estas palabras en algún léxico o gramático; no lo he encontrado igual, pero se explica de modo similar. Podría ser suya la definición. 
Quevedo vuelve a copiar un texto de Menaechmi ${ }^{57}$. Reparó en él después de los anteriores (cf. vv. 502 y 508) o lo pasó a "su hoja", colocándolo no por orden. No se puede saber. Copió dos versos o, por mejor decir, una parte de cada uno ${ }^{58}$ y se limitó a añadir "Esta era la señal". La señal de que el convite hubiese acabado era que Menecmo salía a la calle con su corona. La expresión en la que repara Quevedo es, a nuestro juicio, sublatum est convivium, que se correspondía bien con "se quitó la mesa", que, por supuesto, implica que la comida o convite ha llegado a su fin, o que "se acabó la fiesta". Los lectores del tiempo de Quevedo sabían muy bien dónde estaba la correspondencia, y Quevedo en la obra para la que estaban destinados estos versos daría las explicaciones pertinentes.

\section{Plavt. Most. 692-693 y 697 \\ prandium mihi uxor perbonum dedit, nunc dormitum iubet me ire: minume. \\ Non bonust somnus de prandio. apage.}

Copia Quevedo tres versos de Mostellaria, comedia de la que ya había seleccionado algunos versos anteriores ${ }^{59}$, pero en esta ocasión no añade nada más ${ }^{60}$. Él debe de saber lo que habrá de escribir en el tratado De la común razón de las letras $y$ lenguas, que, al parecer, como ya hemos señalado, quería dar a la luz.

Simón dice que ha comido muy bien y que no va a obedecer a su mujer, que lo manda a dormir, y que no es bueno dormir "después de haber comido". Aunque Quevedo no indica cuál es la expresión española que se corresponde con una latina, parece evidente que esta es non bonust somnus de prandio, "no es buen sueño el de después de comer", sobre todo, después de haber comido -y más

${ }^{57}$ Antes hemos visto los versos 153 y 155, y 471 . Ahora regresa al 463 y siguiente.

${ }^{58}$ Dice así: sed quid ego video? Menaechmus cum corona exit foras. I sublatum est convivium, edepol venio adversum temperi. "Pero ¿qué estoy viendo? ¡Es Menecmo que sale con una corona en la cabeza! Ya se ha levantado la mesa. ¡Por Pólux, vengo a buscarlo en el momento preciso!”. Bravo (1995: I 642).

${ }^{59} \mathrm{Vv} .475,502$ y 508.

${ }^{60}$ Omite los versos 694-696. El pasaje completo dice así: prandium mibi uxor perbonum dedit, I nunc dormitum iubet me ire: minume. I non mihi forte visum ilico fuit, I melius quom prandium quam solet dedit:/ voluit in cubiculum abducere me anus. I non bonust somnus de prandio. Apage. "¿Qué comida tan exquisita me ha servido hoy mi mujer! Ahora quiere que me vaya a dormir. ¡ $\mathrm{Ni}$ hablar del asunto! Enseguida me di cuenta de que no fue casual que me sirviera una comida mejor que la de costumbre. Quería llevarme a la cama la vieja. No es bueno dormir después de comer. ¿Quita de aquí!”. Cf. Bravo (1995: II 196). En los versos intermedios omitidos por Quevedo, Simón deja claro que había advertido que su mujer con esa comida tan exquisita lo que quería era llevarlo a la cama. 
concretamente cenado- exageradamente. Se convirtió en tópico que explotó también, y muy bien, nuestro Quevedo ${ }^{61}$.

\section{5.a. PlaVt. Trin. 345}

Pol pudere quam pigere praestat, totidem litteris ${ }^{62}$.

Quevedo ofrece el "dicho” español: "Más vale vergüenza en cara que mancilla en corazón”, que corresponde, aunque no literalmente, a la idea expresada en el verso plautino. Como es lógico, aunque copia el verso completo, omite totidem litteris, pues no es pertinente, ni está en el refrán español ${ }^{63}$.

\section{5.b. PlaVT. Trin. 355}

Deum virtute habemus.

Quevedo se ha limitado a reproducir estas tres palabras, entre ellas el verbo habemus, cuyo complemento omite ${ }^{64}$. La expresión latina que interesa a don Francisco es Deum virtute, "por la ayuda de los dioses", 'gracias a los dioses', que pasa en español a 'gracias a Dios ${ }^{\prime 65}$. No precisaba de explicación. La semejanza entre las lenguas es evidente.

${ }^{61}$ Por otra parte, 'comida muy buena' (prandium perbonum) o 'ahora me manda ir a dormir' (nunc dormitum iubet me ire) son igualmente expresiones latinas que en español son semejantes. Sin embargo, no parece que sean estas en las que pensó Quevedo.

62 "Pues más vale, por Pólux, avergonzarse que arrepentirse, aunque las dos palabras tengan el mismo número de letras". Bravo (1995: II 614). Se refiere, lógicamente, a que pudere / pigere, como pudet / piget, tienen el mismo número de letras. Filtón está utilizando este sabio dictum muy a su favor.

${ }^{63}$ Este juego de verbos y sus significados se mantiene desde Plauto. Cf. por ejemplo el symbolum XXV (de Fl. Anicius Iustinianus): Quod pudet hoc pigeat, en Reusner (1602: 92-97).

${ }^{64}$ Así dicen los versos 355s.: Deum virtute habemus et qui nosmet utamur, pater, / et aliis qui comitati simus benevolentibus. "Gracias a Dios, padre, tenemos para vivir nosotros y para ser generosos con nuestros amigos". Bravo (1995: II 615). No es necesario decir que las dos oraciones de relativo sustantivadas constituyen el CD de habemus. Su traducción literal podría ser: "tenemos no solo de lo que nosotros mismos podamos servirnos, sino también con lo que servir a otros amigos". En ambos casos las introduce un qui, ablativo arcaico del pronombre relativo. Por otra parte, en los versos 346-348 encontramos los mismos términos (deum virtute y habemus) repartidos en dos versos: Edepol, deum virtute dicam, pater, et maiorum et tua / multa bona bene parta habemus, bene si amico feceris / ne pigeat fecisse, ut potius pudeat si non feceris. "Gracias a los dioses, padre, a nuestros antepasados y a ti, tenemos una gran fortuna, honestamente adquirida, de manera que nos arrepentiríamos menos de haberle hecho un favor a un amigo que nos avergonzaríamos de no habérselo hecho". Bravo (1995: II 614).

${ }^{65}$ McDonnell (2006: 95-104), en el apartado que lleva por título "Hellenization and AretéSemantic borrowing", dedica un detenido estudio a esta expresión, creación latina, y más exactamente plautina, y ofrece, entre otros, el juicio de Ferguson (1958: 162), que la llama "colosal oxymoron", al no ser la virtus propia de los dioses. 
5.c. PlaVt. Trin. 492-494

Salillum animae qui quom extemplo emisimus,

aequo ${ }^{66}$ mendicus, atque ille opulentissimus,

censetur censu ad Acherontem mortuus.

Quevedo en este texto, el último de su selección, copia estos tres versos y, después de ellos, escribe: "Decimos que el alma sirve de sal solamente al inútil, que solo le conserva el cuerpo".

No se ve clara, a primera vista, la relación que tienen con el texto sus palabras; no se entiende bien la referencia a la inutilidad: "que el alma sirve de sal solamente al inútil".

Sin embargo, sí podemos afirmar que Quevedo leyó el texto tal y como lo hemos editado y tal como lo encontramos en el Rebusco; así estaba también en algunas ediciones.

En cuanto al término salillum, no suele estar presente, por lo general, en la mayoría de ellas. Los editores prefieren satillum, la lectio del palimpsesto plautino ${ }^{67}$. Nosotros nos limitamos, lógicamente, al texto que, sin duda, llamó la atención de Quevedo, y que copió e interpretó. Contaba con los conocimientos pertinentes y, sin duda, semejantes a los que llevaron a Plauto a escribir lo que escribió (si es que Plauto escribió salillum). Volveremos sobre ello.

Es bastante claro, también a primera vista, que la expresión con la que encontraba semejanza en español Quevedo era salillum animae, "el salero del alma." Lo puede corroborar el que Erasmo lo incluya en sus Adagid ${ }^{68}$, al explicar que el personaje de Plauto, Filtón, llama al hombre salillum animae, sintiendo que es brevísima su vida, algo así como la sal que en un banquete se le añade a cada cosa. Reproduce Erasmo los versos 490-494, incluyendo los dos previos, y finaliza advirtiendo que

${ }^{66}$ Hemos editado aequo en vez de aeque, que se lee en el manuscrito, porque creemos que Quevedo escribió o quiso escribir aequo. El texto que, con casi total certeza, leyó mostraba aequo, y quien lo comentaba, Taubmannus, defendía esta lectura. Sin embargo, atque apoya aeque, que se lee en la mayoría de ediciones.

${ }^{67}$ El palimpsesto de Plauto ofrece satillum, que llevó a Ritsch a la conjetura sitellum; Berg prefirió stalagmium y Fritzsche scintilla o scintillula; salillum está en algunos manuscritos y es término que usaría luego Catulo 29.19; cf. Wagner (1872: 61). Neilson (1876: 7s.) rechaza sitellum de Ristch y defiende satillum (de satis, como tantillum de tantus), que indicaría que los hombres son meros maniquíes, que, cuando exhalan su "pequeña suficiencia de vida" -our little sufficiency of life-, en el Hades valen tanto el mendigo como el rico. En las ediciones también leemos aeque. Y en cuanto a qui del verso 492, se suele sustituir por quam, cuyo antecedente sería animae. Menos importancia tiene para nuestro objetivo leer Acherontem/Acheruntem, mortuus/ mortuos.

${ }^{68}$ Cf. Chiliadis v, Centuria I vii. En la edición de 1550, en col. 1197. 
en el último verso podría haberse escrito un nombre propio, Pelops, Croesus, o algún otro similar que fuera bisílabo, puesto que al senario le faltan dos sílabas ${ }^{69}$.

Ciertamente, hay un adagio, hay una expresión castellana, "salero del alma", igual que se leía en Plauto, mas el adagio no da razón de las palabras de Quevedo. Este ni ha tomado el texto de Erasmo (en el que se lee quam y no qui), ni hace referencia a la brevedad de la vida del hombre.

Quevedo copia solo tres versos, omitiendo los dos anteriores, que son parte integrante del período y necesaria, a nuestro juicio, para el entendimiento del mismo. Los versos (490-494), que están en boca de Filtón, establecían una comparación diferencial entre, por una parte, los dioses, que son ricos, que nadan en la opulencia y disfrutan del poder (no siempre bien utilizado, como sugiere factiones), y, por otra, los homúnculos, hombrezuelos, pobres seres (vv. 490-491). De estos, ciertamente, ni los que gozan de riqueza pueden considerarse dichosos, porque, cuando mueren y llegan al Aqueronte, de nada les sirve; son como los mendigos (492-494):

\section{Dei divites sunt, deos decet opulentia, et factiones: verum nos homunculi salillum animae qui cum extemplo amisimus, aequo mendicus, atque ille opulentissimus, censetur censu ad Acherontem mortuus ${ }^{70}$.}

Las palabras clave son, sin duda, nos homunculi salillum anima ${ }^{71}$. Pueden interpretarse: "nosotros (somos) unos pobres seres, el salero del alma", en que salillum animae sería aposición a homunculi, o "nosotros, pobres seres, somos el salero de alma", atributo. En ambos casos, la idea es la misma: no somos ricos, no tenemos poder y, si tenemos riqueza, desaparecerá al morir, cuando ya no esté en nosotros el anima. Es decir, somos nada; no somos, desde luego, dioses. Todo acaba con la igualatoria

${ }^{69} \mathrm{Cf}$. Salillum animae. In ea scena Philto hominem vocat 'Salillum animae', sentiens hominis brevissimam esse vitam, videlicet quantulum salis cuique in convivio apponitur. Locus Plautinus sic habet: Dei divites (...) Acherontem mortuus. Quamquam extremo senario desunt duae syllabae, Pelops censetur, aut censetur Croesus, aut aliquid simile. En la edición de Adagia de 1550 se lee en col. 1197.

${ }^{70} \mathrm{El}$ texto es el de Taubmannus (1605: 1150). Literalmente puede decir en nuestra lengua: "Los dioses son ricos; a los dioses conviene la opulencia y las facciones; nosotros (somos) hombrezuelos, el salero del alma, que, cuando nada más la perdemos, con igual censo es censado en el Aqueronte, una vez muerto, el mendigo y el más opulento." El complemento de amisimus es, lógicamente, "el alma", lo que llevó a sustituir muy pronto qui por quam, sustitución que ha tenido una buena acogida, aunque no total. El texto que lee Quevedo tiene qui, cuyo antecedente es homunculi. Si nos limitamos al texto copiado por Quevedo, podría decir algo así: "(Nosotros) que cuando nada más perdemos el salero del alma, con igual censo es censado en el Aqueronte, una vez muerto, el mendigo y el más opulento". A nuestro juicio, no se detuvo a entender el texto que había copiado; solo le interesaba el salillum animae. Lo que importa en ambos casos es ver la relación de salillum con las palabras de Quevedo.

${ }^{71}$ Suelen estar en mayúscula en muchas ediciones; en la de Taubmannus también. 
muerte. La expresión de Plauto, si escribió salillum, es, ciertamente, brillante ${ }^{72}$, pues pudo con ella decir muchas más cosas.

Ciertamente, si acudiéramos a una ecuación, podríamos decir que si salero es lo que contiene sal, si se llama salero al cuerpo, que es el recipiente del alma, se podrá concluir que el alma es igual a sal. Esa condición de ser el alma como la sal es la que llevaría a Plauto a crear una expresión que puede aplicarse a los hombres, a algunos hombres. Podría ser por lo "insignificante" que es la sal, aunque, ciertamente, no lo es tanto. Sin embargo, hay explicaciones más sabias y adecuadas, filosóficas, podríamos decir.

El filósofo Crisipo había dicho que el anima del cerdo era como la sal, pues solo servía al animal para conservar su carne. Esta aserción, que también se atribuye a otro filósofo, Cleantes, debía de conocerla Plauto.

Por tanto, si los hombres - por lo menos, los homunculi en los que piensa el Filtón de Plauto- son el "salero", es decir, el continente, el cuerpo en el que se encierra un anima que solo sirve de sal, se puede deducir que son como los cerdos. Su anima, como la de este animal, solo les vale para mantener su cuerpo.

Plauto, pues, pudo escribir salillum. No es nada extraño que conociera lo "dicho" por el filósofo. Las ideas, también los libros, se difundían. Atribuir a los hombres, a algunos al menos, un anima semejante a la del cerdo, se compadece con el ingenio plautino. Hablar del hombre como "salero -pequeño- del alma" o "vasija de un alma de cerdo" era, verdaderamente, un acierto. El salillum animae no era solo un adagio que hablaba de la brevedad de la vida, sino también de la estulticia e inutilidad del hombre, que tiene "alma de cerdo" y a este se asemeja.

Antes de llegar a Quevedo, que así pudo interpretarlo, recordaremos los textos fundamentales que transmitían lo que decía Crisipo o Cleantes. Plauto conocía, diríamos, los textos originales; Quevedo lo que otros transmitieron. Gracias a ellos pudo interpretar la expresión plautina.

En cuanto a la autoría de Crisipo, que es la generalizada, el texto más citado es el de Cicerón, De natura deorum 2, 160. Decía Cicerón que los dioses habían dado los animales al hombre para su beneficio, afirmando que lo propio y exclusivo del cerdo (sus) era proporcionarle comida y que, como decía Crisipo, para que no se pudriera, se le dio como sal el anima (cui [sc. suo] quidem, ne putesceret, animam ipsam pro sale datam dicit esse Chrysippus). Concluía reconociendo que la naturaleza no engendró un animal más fecundo que el cerdo para proporcionar alimento a los hombres ${ }^{73}$.

${ }^{72}$ Si escribió satillum, de satis, diría: echamos fuera "lo bastantillo de alma", lo poquito de alma. Bravo (1995: II 620) traduce "débil aliento que nos anima".

${ }^{73}$ CIC. nat. deor. 2, 160: Sus vero quid habet praeter escam? cui quidem, ne putesceret, animam ipsam pro sale datam dicit esse Chrysippus; qua pecude, quod erat ad vescendum hominibus apta, nihil genuit natura fecundius. Varrón dice algo similar sin nombrar a Crisipo, a saber, que la naturaleza ha ofrecido 
En cuanto a la autoría de Cleantes, es Clemente de Alejandría quien decía en Stromata 7, 6 que, aunque los animales no están destinados a alimentar al hombre, sí lo están los que no trabajan (es decir, los inútiles), y que entre los que avalan su opinión está el filósofo Cleantes, que dijo que el cerdo había recibido un alma como sal, para evitar que su carne se corrompiera, añadiendo que unos se alimentan de su carne -es decir, los sacrifican-, porque no les son útiles para otra cosa, y otros lo hacen porque el cerdo destroza las cosechas ${ }^{74}$. Pero es hora de regresar a Quevedo.

Cuando Quevedo escribe detrás de los tres versos de Trinummus: "Decimos que el alma sirve de sal solamente al inútil, que solo le conserva el cuerpo", está diciendo que hay hombres inútiles cuya alma les sirve, como al cerdo la suya, para conservar el cuerpo. Y también está diciendo indirectamente que conoce lo que transmitía Cicerón, también Varrón y, sobre todo, lo que transmitía Clemente de Alejandría. Él no cita a ningún autor, pero la mención del inútil, que hace pensar en la inutilidad del cerdo por no valer para trabajar, es de este último. Quevedo, a nuestro juicio, entendió, uno de los primeros, si no el primero, mejor que nadie este texto de Plauto ${ }^{75}$. Con salillum animae sugería que algunos hombres, si no todos, son como cerdos, tienen un anima de cerdo.

Creemos que el comentario de Taubmannus debió de conducir los pasos y la mente de don Francisco a explicar esta expresión, como también lo había hecho con relación a un pasaje nunca antes explicado de Poenulus ${ }^{76}$.

Ciertamente, Taubmannus, al comentar Nos homunculi salillum animae, recoge lo que interpretaba Lambinus: "somos el vasito de la sal", a saber, corpuscula animata, insistiendo en que nuestros cuerpos son como vasijas de las almas, y que se dijo salillum por comparación con las mesas sencillas y pobres, en las que la sal

a los cerdos para dar de comer, y que su alma sirve para conservar su carne. Cf. VARRO rust. 2, 4.10: Suillum pecus donatum ab natura dicunt ad epulandum; itaque iis animam datam esse proinde ac salem, quae servaret carnem.

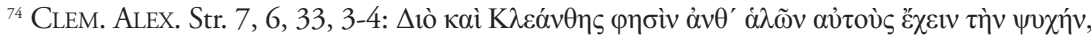

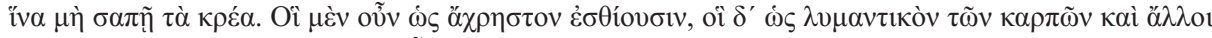

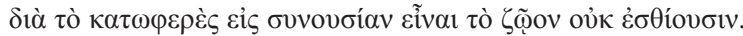

${ }^{75}$ El "decimos" de Quevedo parece indicar que así se decía, y que sería al encontrar el texto de Plauto cuando descubrió que ahí estaba el origen de lo que decían en español. Él vio en Plauto la inutilidad del cerdo y la de tantos hombres. De la estupidez - no de la inutilidad- del cerdo hablaba Huarte de San Juan, en su Examen de ingenios, cap. VI, recogiendo lo que leía en Galeno: que los que quieren ser muy sabios no deben estar cargados de grasa y pringue, sino flacos y macilentos, ... lo cual confirma el puerco, el más estulto entre todos los brutos animales, que por la mucha carne que tiene, su anima, dijo Crisipo, servía no más que de sal, para que no se le corrompiese el cuerpo. Cf. Huarte (1594: 87v-88r). Quevedo también sabía que Persio hablaba de un personaje cuya gruesa barriga (aqualiculus pinguis, 1.57) le impedía tener buen juicio, dado que -como ya decía Plinio, nat. 11, 79, 3- los gordos son de ingenio escaso, y el sustantivo usado por el volaterrano aparece en Isidorus (IsID. orig. 11.1.136) aplicado al cerdo. Puede verse lo que sobre el término aqualiculus se halla en Del Amo Lozano (e.p.: 2-7).

${ }^{76}$ Cf. Moya (2019: 601-605). 
se añadía al pescado, aduciendo un texto de $\mathrm{Horacio}^{77}$. No parece, en efecto, la explicación adecuada a un texto de Plauto, y, desde luego, no pudo sugerir a Quevedo la idea de "inutilidad". Quizá por eso Taubmannus aporta la otra explicación, a saber, que el alma es para nuestro cuerpo como la sal, y que al cuerpo, como a la carne, si no se le echa sal, se pudre; así los cuerpos, una vez echada el alma, se corrompen ${ }^{78}$. Y remite también al adagio de Erasmo y, asimismo, por si alguien está interesado, a Palmer, al folio 235 de su Spicilegium, en donde -informa Taubmannus-, comentando los versos 270s. del Eunuchus de Terencio, interpretaba, siguiendo a Scoppa, summum suum como summum porcorum, y citaba aquello de Crisipo sobre el anima del cerdo ${ }^{79}$.

Este comentario de Taubmannus ${ }^{80}$, aunque no sabemos si Quevedo leyó a Palmer, pudo mover la mente de don Francisco. Su ingenio descubrió el de Plauto. Dedujo que allí estaba aludiendo al cerdo, y no veía en él que fuese un regalo de la naturaleza, al poder servir de alimento a los hombres, sino que vio al animal inútil, cuya anima no servía para otra cosa que para conservar su carne, aunque luego sirviese de alimento ${ }^{81}$. Lo deja muy claro "Decimos que el alma sirve de sal solamente al inútil, que solo le conserva el cuerpo". Esos hombres inútiles son como los cerdos; su anima es como la de estos animales; no es, por tanto, un alma racional. En castellano se podría decir que alguien era "un salero del alma" o que tenía "alma de cerdo".

Quevedo entiende bien lo que decían Crisipo o Cleantes; había leído, como es bien sabido, a Cicerón y, sin duda, también a Clemente de Alejandría ${ }^{82}$. Unas

${ }^{77}$ Cf. Taubmannus (1605: 1156): Nos homunculi salillum animae. Sumus vasculum salis, inquit Lambinus, i., sumus corpuscula animata. Nam corpora nostra sunt tanquam animarum vascula. Salillum animae dixit fortasse translatione sermonis facti a mensis pauperum, quae sunt perquam tenues et sine apparatu. Eis enim sal pro obsonio est. Horat. 2. Oda $16<13$ s. $>$ : Vivitur parvo bene cui paternum / splendet in mensa tenui salinum, etc.

${ }^{78}$ Así sigue diciendo: Licet enim dicere, Plautum eo spectasse, animam corpori nostro esse pro sale. Quemadmodum enim carnes pecudum, si diu serventur sine sale, putrescunt: ita et corpora, efflata anima, putore corrumpuntur.

79. Así dice: Vide et Adag. Salillum animae, et si quid forte ad rem faciet, quod scripsit Palmer. Spicileg. fol. 235. super illud Ter. Eun. Act. 2: 2. salsus anima (ut quidem ipse legit falsus animi) atque illud item, Plurima salute, Parmenonem Summum suum impertit Gnatho <vv. 270s.>, ubi, summum suum, interpretatur cum Io. Scoppa, Summum porcorum: laudatque illud vulgatum de Chrysippo, qui dixerit. Sui pro sale animam datam, ne putisceret, etc.

${ }^{80}$ Quevedo tuvo, sin duda, ante sus ojos el texto de Plauto en la edición de Taubmannus (en ella se leía qui y también aequo) y leyó el comentario, pero la interpretación de salillum animae es, a nuestro juicio, suya, aunque partiese de Taubmannus. Otros comentaristas han insistido en que Crisipo está en el origen de la expresión, pero sin dar razones. Valga de ejemplo Ruffner (1807: 442), que decía que el salero del alma es el cuerpo, que no puede sobrevivir sin alma, como tampoco la carne sin sal puede evadir la putrefacción, añadiendo que Plauto pudo pensar en lo de Crisipo. Pero nada más.

${ }^{81}$ Como es natural, hay muchos textos en los que se alaba el cerdo y su carne.

${ }^{82}$ Las citas y menciones de Cicerón son numerosas. Sobre las citas en latín, cf. Moya (2014: 257-266). Sobre Clemente de Alejandría tenemos el testimonio de Quevedo, que en Nombre, Origen, Intento, Recomendación y Descendencia de la Doctrina estoica, lo menciona en la relación de nombres de estoicos, dejando claro que lo ha leído. Dice así: "Autorizó la doctrina Estoica Clemente Alexandrino, 
palabras del filósofo Emmanuel Kant pueden servir de apoyo a su interpretación. Las leemos en el opúsculo Anuncio de la próxima conclusión de un Tratado de paz perpetua en la filosofía", bajo el epífrafe "Del grado ínfimo de la naturaleza viviente del hombre hasta su grado supremo, el de la filosofía" ${ }^{34}$. Así comienzan en traducción de Rogelio Rovira ${ }^{85}$ :

Dice Crisipo en su enérgico lenguaje de estoico: La naturaleza ha dado al cerdo un alma, en vez de sal, para que no se corrompa. Este es, pues, el grado ínfimo de la naturaleza del hombre antes de toda cultura, a saber: el instinto animal.

No habla Kant de animales inútiles, pero sí avala que tener un anima como sal, el ser un salillum animae, un "salero del alma", es estar en ese grado ínfimo; es asemejarse a un animal inútil -y también estulto- como el cerdo. Así lo había visto don Francisco de Quevedo.

\section{A MODO DE CONCLUSIÓN}

El recorrido y parada en estos textos, que llamaron la atención de Quevedo por encontrar en ellos una semejanza con nuestra lengua, ha corroborado la familiaridad de nuestro autor con los textos clásicos, en esta ocasión con los del gran comediógrafo latino, al que conocía bien; él, sin duda, lo inspiró y en él encontraría muchas veces a su alma gemela; a él acudió también como lingüista.

Queda patente, asimismo, que Quevedo conocía en profundidad la lengua española y la latina. En los textos elegidos son evidentes, en la mayoría de los casos, las semejanzas entre ambas lenguas; en otros, hemos intentado descubrirlas.

Parece lógico, como podemos apoyar ahora con nuestro análisis, que estos textos fuesen destinados al tratado De la común razón de las letras y lenguas, que menciona en España defendida.

En estos "apuntamientos" se comprueba de nuevo que Quevedo tenía madera de humanista, que conoce las fuentes y acude a ellas; destaca, de manera especial, en su interpretación de salillum animae, que tiene detrás importantes lecturas, aunque, como hemos dicho en otras ocasiones, a don Francisco le faltaban algunas cualidades imprescindibles en un humanista. A veces su "ingenio", la rapidez de su pensamiento

como se conoce leyendo sus admirables escritos"; al final de La defensa de Epicuro ofrece en latín una interesante y amplia cita de Stromata, que avala su afirmación; cf. Buendía (1958: 978 y 991).

${ }^{83}$ Una especie de testamento filosófico, en palabras de Rovira (2004: 12). Kant lo dio a la luz en 1796.

${ }^{84} \mathrm{El}$ texto alemán aparece in fronte debajo del epígrafe "Von der untersten Stufe der lebenden Natur des Menschen bis zu seiner höchsten, der Philosophie".

${ }^{85}$ Cf. Rovira (2004: 17). 
y la prisa lo traicionan, y de ahí los pequeños fallos en la lectura o copia de los textos, aunque en este caso solo de notas personales se trata. Sin embargo, aunque probablemente no fue, por las razones mencionadas, el gran humanista que hubiese querido, sí fue, afortunadamente, el gran Quevedo que conocemos.

Y para acabar, creemos que Quevedo ofrece, en sus pocas y acertadas palabras, un testimonio muy claro para defender que la lectio plautina es salillum. Pese a la autoridad del palimpsesto, consideramos que este término y expresión, de difícil comprensión, debió de ser muy pronto sustituida por la lectio facilior, que solucionaba la dificultad, satillum. Pese a haber antecedentes, él, a nuestro juicio, da en la diana y logra una importante aportación a la filología clásica. Salillum es el término que, en nuestra opinión, debe ser restituido. Esta no es la única aportación que don Francisco tiene en su haber ${ }^{86}$. Quedan más por descubrir.

\section{BIBLIOGRAFÍA}

Adagiorum Opus (1550) = Adagiorum Opus. Des. Erasmi RoterodAmI, ex postrema autoris recognitione, Lugduni, apud Sebastianum Gryphium.

Amo LozAno, M. del (2015 [en prensa]): "Cuestiones léxicas en las primeras traducciones de Persio», Actas del VI Congreso internacional de humanismo y pervivencia del mundo clásico, Alcañiz.

Astrana Marín, L. (1940): Ideario de don Francisco de Quevedo, Biblioteca Nueva, Madrid.

Astrana Marín, L. (1945): Francisco de Quevedo. Obras completas en Prosa, Aguilar, Madrid.

Blecua, J. M. (1999 [= 1969]): Francisco de Quevedo. Obra poética, vols. I-III, Castalia, Madrid.

Bravo, J. R. (1995): Plauto. Comedias I y Comedias II, Edición de J. R. Bravo. Traducción de J. R. Bravo, Madrid, Cátedra.

Buendía, F. (19584): Don Francisco de Quevedo y Villegas. Obras completas, Tomo I. Obras en Prosa, Aguilar, Madrid.

Calderini, D. (1601): Cf. Martialis (1601).

CONde PARRADO, P. P. (2017): «Argutae et litteratae: una nueva mirada sobre el intercambio epistolar entre Francisco de Quevedo y Justo Lipsio (1604-1605)», en Ma. J. Alonso Veloso (ed.), Quevedo en Europa, Europa en Quevedo, Academia del Hispanismo, Vigo, pp. 33-78.

McDonnell, M. (2006): Roman Manliness: "Virtus" and the Roman Republic, Cambridge.

ERASMus (1550): Cf. Adagiorum Opus.

Fantham, E. (1972): Comparative Studies in Republican Latin Imagery, Toronto, University.

FERGUSON, J. (1958): Moral Values in the Ancient World, London.

Fernández-Guerra y Orbe, A. (1859): Obras de Don Francisco de Quevedo Villegas, Colección Completa, Tomo segundo, B.A.E., Madrid.

${ }^{86}$ Puede verse Moya (2015: 194-206, en especial 202-206). 
Gronovivs, J. F. (1829) = M. ACCI PlaVti Comoediae ex editione J. F. Gronovil cum Notis et Interpretatione in usum Delphini, variis lectionibus, notis Variorum, recensu editionum et codicum et Indice locupletissimo accurate recensuit. Volumen quartum, Londini, curante et imprimente A. J. Valpy.

Hernández Fernández, M. (2006): El Teatro de Quevedo [Tesis Doctoral], Universidad de Barcelona [http://diposit.ub.edu/dspace/handle/2445/35035. Consultada 4 de septiembre de 2020].

HuARTE DE SAN JUAN (1594): Examen de ingenios (...) Agora nuevamente enmendado por el mismo Autor y añadidas muchas cosas curiosas y provechosas. Impresso en Baeça, en casa de Juan Baptista de Montoya.

Jauralde, P. (1998): Francisco de Quevedo (1580-1645), Castalia, Madrid.

KanT, I. (1998): Anuncio de la próxima conclusión de un Tratado de paz perpetua en la filosofia, edición bilingüe de Rogelio Rovira, Ediciones Encuentros, Opuscula Philosophica, Madrid.

Lambinvs, D. (1622) = M. ACCIVS PLAVTVS ex fide atque auctoritate complurium librorum opera Dionys. LAmbini (...) emendatus (...) explicatus, Genevae, apud Samuelem Crispinum.

LÓpez PozA, S. (1991): «Quevedo y las obras Patrísticas», BBMP 67: 75-156.

MarTialis (1601) $=$ M. Valerii MARTIALIS Epigrammatum libri XIV Domitii CALDERINI Commentariis perpetuis \& Georgii Merulae observationibus illustrati. (...), Parisiis, apud Claudium Morellum.

Menéndez Pelayo, M. (1950): Bibliografia Hispano-Latina Clásica, v. III, Gredos, Madrid.

Moya Del BAÑo, F. (2014): Quevedo y sus ediciones de textos clásicos. Las citas grecolatinas y la Biblioteca Clásica de Quevedo, Editum, Murcia.

Moya del Baño, F. (2015): «Don Francisco de Quevedo, 'filo-filólogo’ clásico», en Humanismo y Pervivencia del Mundo Clásico, V. Homenaje al Profesor Juan Gil, Alcañiz-Madrid, v. I, pp. 185-209.

Moya del BaÑo, F. (2019): «La presencia de Plauto en Quevedo», en S. López PozA et alii (eds.) Docta y sabia Atenea. Studia in honorem Lía Schwartz, Universidade, SIELAE, A Coruña, pp. 593-611.

Moya-Miralles (2018): Cf. Quevedo.

Nebrija, A. (1615) = Dictionarium Aelii Antonii NEBRISSENSIS (...), opera vero et industria magistri Ioannis Lopez Serrani, Matriti, apud Ioannem de la Huerta.

NeILSON, ED. L. (1876): Four Notes on Plautine Words: Inconciliare, Mendicarier, Sitellum, Ferentarius, Geenock.

Quevedo, F. (2018) = Francisco de Quevedo. España defendida, edición crítica y anotada por Francisca Moya del Baño y José Carlos Miralles Maldonado, SiElaE, A Coruña.

RamsaY, W. - Ramsay, G. (2020=1869): The Mostellaria of Plautus, Salzwasser Verlag GmbH, Frankfurt.

REUSNER N. (1602) = Nicolai REUSNERI Leorini Silesii Symbolorum Imperatorium Classis secunda qua continentur Symbola Impp. Caesarumque Romanorum Graecorum, a Fl. Constantino Magno, usque ad Carolum Magnum, primum Caesarem Germanicorum (...) Francofurti, Sumptibus ac Typis Ioannis Spieslii et heredum Romani Beati.

RILEY, H. TH. (1852) = The Comedies of Plautus, literally translated into english prose with notes by RILEY, v. II, London.

RufFner, Chr. (1807) = M. A. PlavTVs. Sämmtliche Lustspiele aus dem Lateinischen metrisch übersetzt und mit Anmerkungen begleitet von RufFner, Dritter Band, Wien.

ROVIRA, R. (2004): Cf. KANT. 
Tavbmannvs, F. $(1605)=$ M. ACCI PLAVTI Lat. Comoediae facile principis Fabulae XX. Superstites cum novo et luculento Comentario doctorum virorum opera Friderici TAubMani (...) Excudebat Wolf. Meisnerus.

TARSIA, P. DE (1997=1663): Vida de don Francisco de Quevedo y Villegas. Reproducción facsimilar por M. Prieto Santiago. Prólogo de F. B. Pedraza Jiménez, Universidad de Castilla la Mancha.

WaGner, Wh. (1872): T. Macci Plauti Trinummus, with Notes critical and exegetical, Cambridge-London. 